\title{
Rotavirus, adenovirus, and non-viral enteropathogens in diarrhoea
}

\author{
T VESIKARI, M MÄKI, H K SARKKINEN, P P ARSTILA, AND P E HALONEN \\ Department of Paediatrics, Tampere Central Hospital, and Department of Virology, University of Turku, \\ Finland
}

SUMMARY The aetiology of rotavirus and adenovirus in acute gastroenteritis was studied in a prospective series that comprised 283 children admitted consecutively with diarrhoea during a 1 -year period. Rotavirus was associated in $49 \%$ of the cases by solid-phase radioimmunoassay and electron microscopical examination of stool specimens, or by serology. Adenovirus was detected by radioimmunoassay in the stool specimens of $29(11 \%)$ patients, including 8 cases of possible dual infection with rotavirus. Rotavirus infections showed a typical age distribution and seasonal clustering between January and June, whereas the adenovirus-associated cases did not form a distinctive subgroup. Enteropathogenic bacteria were found in $10 \%$ of cases, and were nearly as common in association with rotavirus infection as not. Respiratory symptoms accompanied diarrhoea in $34 \%$ of the patients with rotavirus and in $25 \%$ of those with neither rotavirus nor adenovirus. Therefore we could not confirm the existence of a 'rotavirus syndrome', nor could we confirm an association of respiratory symptoms with rotavirus infection. Use of antibiotics before the onset of diarrhoea was more common among those with non-viral diarrhoea $(23 \%)$ than in the rotavirus group (13\%). Rotavirus infections appeared to be common among cases of 'antibiotic-induced' diarrhoea.

Since its discovery in $1973^{12}$ rotavirus has been well documented as a causative agent of infantile gastroenteritis. ${ }^{34}$ Occasionally rotaviruses are encountered with other enteropathogens, but their significance in such dual infections is unknown. ${ }^{5}$ Also uncertain is the role of rotaviruses in the aetiology of respiratory symptoms often associated with rotavirus diarrhoea. ${ }^{6-8}$

Interest in adenoviruses as significant enteric pathogens in children has recently been revived. ${ }^{9}$ Electron microscopy (EM) has contributed a great deal to this increased interest, since adenoviruses are found in the stools more often by EM than by isolation ${ }^{1011}$ and there now appear to be several types of new 'noncultivable' adenoviruses. ${ }^{12}$ Again, the association of the virus in the faeces with the disease is questionable. Adenoviruses may be found in the stools in the absence of diarrhoea, with or without respiratory symptoms. ${ }^{1314}$ Adenoviruses have also been found in diarrhoeal stools in combination with other enteropathogens. ${ }^{5}$

In the present study we have used the newly developed solid-phase radioimmunoassay (RIA) techniques which are sensitive and specific for the detection of rotaviruses ${ }^{15}$ and adenoviruses ${ }^{28}$ in stools. We have studied the presence of rotavirus and adenovirus by these methods, and by viral serology, during a 1-year period in children admitted to hospital with diarrhoea. Additionally, bacterial enteropathogens were searched for from the same patients. We have specifically monitored respiratory symptoms during the diarrhoea and we recorded the use of antibiotics so as to correlate these factors with the aetiology of diarrhoea.

\section{Materials and methods}

Patients. The study group comprised 283 children admitted consecutively for diarrhoea to this hospital during a period of one year (1 December 1977 to 30 November 1978). The patients were chosen if they had diarrhoea on admission, irrespective of other concomitant diseases. Children who had been treated with antibiotics before the onset of diarrhoea were included too. Those who developed diarrhoea while in hospital were termed nosocomial infections and were excluded from the study. If a child was admitted for a second time with diarrhoea he was 
regarded as a new entry; there were 9 such cases. Three children found to have non-infectious causes of diarrhoea (cows' milk intolerance, bleeding Meckel's diverticulum, and Crohn's disease) were excluded. So finally 280 children were studied.

The parents were asked about the duration of symptoms before the admission, and about the use of antibiotics. Any sign of respiratory infection was registered by nurses in charge of the patient. The diagnosis of otitis media in any patient in hospital was confirmed by middle-ear aspiration. After discharge, the patients were seen again by one physician (M M) at about 4 weeks, and the parents were asked about any illnesses during the interim period.

Specimen collection and storage. Between 1 and 3 stool specimens were collected from each patient every 2 days if possible. No stools for viral studies were obtained from 7 children, but the patients were included in the series for the sake of completeness. Convalescent stage stool specimens were collected from 193 children 4 weeks after discharge from the hospital. All the specimens for viral studies were kept at $-20^{\circ} \mathrm{C}$ and tested retrospectively under code for rotavirus and adenovirus antigens by RIA. Any stool that was positive in RIA, or by serology using a complement-fixation (CF) test (see below), was further studied by EM for the presence of rotavirus and adenovirus particles. Stool specimens for bacteriology were taken to the laboratory in transport medium and were generally cultured the same day.

Serum samples were obtained at the acute stage on the first weekday in hospital and again at the convalescent stage 4 weeks later. Convalescent sera were not obtained from 22 children, but the children are included in the total number of patients.

Solid-phase radioimmunoassay. The solid-phase RIA for rotavirus has been described in detail..$^{15}$ In brief, rotavirus antigen in the test samples was captured on to polystyrene beads precoated with guinea-pig antirotavirus antibody. The presence of antigen was assayed by adding rabbit antirotavirus antibody and ${ }^{125}$ I-labelled sheep antirabbit immunoglobulin. In cases with borderline positive results confirmation was obtained by adding guinea-pig antirotavirus serum before the rabbit antirotavirus antibody and observing the blocking effect. The RIA procedure for adenovirus antigen consisted of analogous steps and reagents. ${ }^{28}$ The sensitivities of the RIA methods were determined to be between 1 and $10 \mathrm{ng} / \mathrm{ml}$ of purified virus protein.

Electron microscopical examination. About $10 \%$ stool suspensions in phosphate buffered saline centrifuged at $2500 \mathrm{rev} / \mathrm{min}$ for 30 minutes were studied. If a RIA-positive specimen was found negative by the first EM, the supernatant was centrifuged at $30000 \mathrm{rev} / \mathrm{min}$ for 90 minutes, and the pellet resuspended in a small volume of distilled water. The negative staining on carbon-coated grids was done with $2 \%$ phosphotungstic acid. The specimens were examined using a JEM 100 electron microscope at a magnification of $30000 \times$. At least 5 grid squares of faecal material of each specimen were studied.

Viral serology. A standard CF test with two full units of complement was used for all serology. For rotavirus serology the antigen preparation was made by growing Nebraska Calf Diarrhea Virus (NCDV) in continuous LLC-MK2 cells in the presence of trypsin. ${ }^{16}$ At 48 hours the cells and the medium were frozen and thawed three times, centrifuged at 2500 $\mathrm{rev} / \mathrm{min}$ for 30 minutes, and the supernatant used as the $\mathrm{CF}$ antigen. The adenovirus $\mathrm{CF}$ antigen was bought from Orion Diagnostica, Espoo, Finland. In addition, the following antigens were used in the standard serology performed on all the paired sera: influenza $A$ and $B$, parainfluenza 1, 2, and 3, respiratory syncytial virus, herpes simplex, varicella zoster virus, cytomegalovirus, mumps, measles, rubella, coxsackie B5, and Mycoplasma pneumoniae.

Bacteriological studies. The following enteropathogenic bacteria were searched for: enteropathogenic Escherichia coli (EPEC), enterotoxigenic (LT) E. coli (ETEC), enteroinvasive E. coli (EIEC), ${ }^{17}$ Salmonella sp., Shigella sp., Yersinia enterocolitica, and Campylobacter jejuni. In addition, cysts of Giardia lamblia were studied from stool specimens using a formalin-ether concentration method.

\section{Results}

The diagnostic criteria for rotavirus-associated and adenovirus-associated diarrhoea were established as follows. RIA of the stools was the primary test for both. For rotavirus, the demonstration of seroconversion or a significant rise in CF antibodies to NCDV was also considered diagnostic of diarrhoea, since it was thought unlikely that such a serological finding was associated with any disease other than gastroenteritis. In contrast, for adenovirus only those positive in RIA were regarded as possible adenovirusassociated cases of diarrhoea, since a diagnostic rise in adenovirus antibodies alone may be found in a number of other clinical conditions as well. In fact, in the present series there were 18 children with diarrhoea and no demonstrable adenovirus in the stools who showed a significant rise in adenovirus CF antibodies over a period of 4 weeks. 
From these criteria there were 128 cases of rotavirus-associated diarrhoea and 29 cases of adenovirus-associated diarrhoea. Of the latter, in 8 children evidence of a concomitant rotavirus infection was also found or, conversely, there were 8 cases of rotavirus-associated cases with simultaneous presence of adenovirus in the stools. Finally, there were 131 cases in which neither rotavirus nor adenovirus could be shown. In 21 instances either the stool specimen or the convalescent serum was missing, so the possibility of rotavirus infection cannot be excluded in these patients. This left 110 cases of non-rotavirus-associated, non-adenovirusassociated diarrhoea with adequate specimens. The total number of children in whom viral studies were complete was 259 , and a diagnosis of rotavirus could be made in $49 \%$ and adenovirus in $11 \%$ of them including dual infections; neither virus was found in $42 \%$ of cases.

Rotavirus-associated diarrhoea. Epidemiologically the rotavirus-associated cases formed a fairly distinct subgroup (Figs 1 and 2). The epidemic season lasted from January to June with a few cases between July and October. There was only one case in an infant aged less than 3 months, and the infection was rare up to 6 months. The peak incidence was between 7 and 12 months, and rotavirus diarrhoea remained common up to age 3 years.

Most children with rotavirus diarrhoea showed seroconversion by CF test with NCDV (Table 1). The seroconversion rate in the RIA-positive cases was $85 \%$. In only 8 of the 104 RIA-positive cases was there no detectable CF antibody, and in 3 others the CF antibody titre did not change. Therefore most of the rotavirus-associated cases appeared to be primary infections. The CF antibody titres in the convalescent sera were generally low (Fig. 3), but there was not much difficulty in serological diagnosis because in most cases the acute stage specimens were negative for NCDV antibody. As expected, EM was found to be less sensitive than RIA for detecting rotavirus in stool specimens (Table 2). Of the 108 RIA-positive specimens rotavirus was found by EM in $88(81 \%)$ cases.

There were no second admissions for rotavirusassociated diarrhoea during the 1-year period. At the convalescent stage none of the initially rotaviruspositive patients had demonstrable rotavirus in the stools (95 tested). Rotavirus was detected at the convalescent stage in one child who initially had had a bacterial diarrhoea (EPEC O 111); in this case there

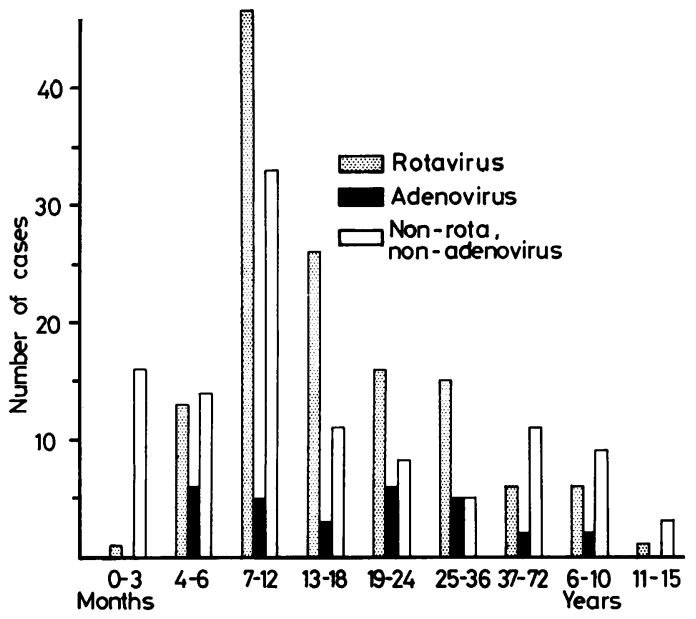

Fig. 2 Age distribution of 259 children who had rotavirus, adenovirus, or non-rotavirus, non-adenovirusassociated diarrhoea.

Table 1 Comparison of radioimmunoassay for rotavirus antigen in the stools with serological studies of paired sera by complement fixation using NCDV antigen in 122 children

\begin{tabular}{lcc}
\hline Serology & RIA-positive & RIA-negative \\
\hline Seroconversion & 88 & 15 \\
Significant rise & 5 & 3 \\
No significant change & 3 & 0 \\
No detectable CF antibody & 8 & 0 \\
\hline
\end{tabular}

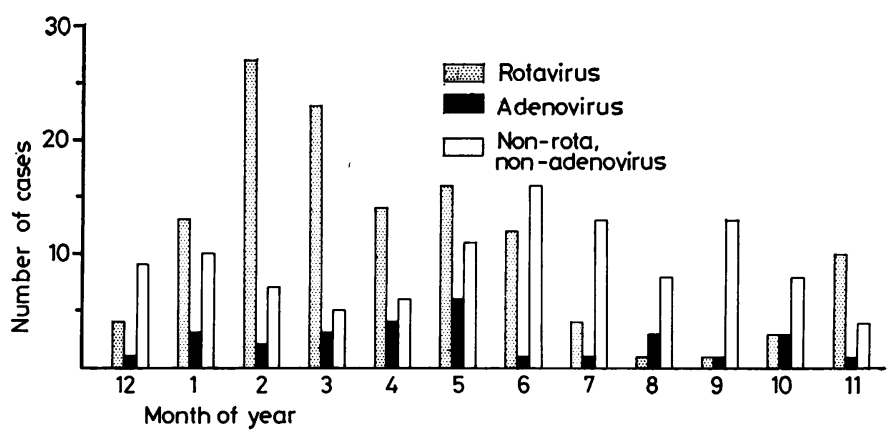

Fig. 1 Seasonal distribution of 259 children admitted with gastroenteritis in whom a viral diagnosis could be made. 
had been a second attack of diarrhoea at home a few days before specimen collection.

Adenovirus-associated diarrhoea. There were 29 adenovirus-positive cases by RIA including cases with evidence of a concomitant rotavirus infection by RIA, and 4 cases with a simultaneous rise of rotavirus antibodies. One other case was associated with $M$. pneumoniae infection. Each of the remaining 20 patients is listed in Table 3.

Of the 20 adenovirus-only cases the presence of adenovirus in the stools was confirmed by EM in 12 instances. The results of the serological tests varied. In 7 patients there was no demonstrable adenovirus CF antibody response. Seroconversion by CF was seen in 8 children, a significant rise of CF titre in 2 more, and in 3 cases there was a high CF titre without rise.

There was some clustering of the adenovirusassociated cases of diarrhoea in the spring (Fig. 1). Eight out of the 20 cases (Table 3) occurred in April

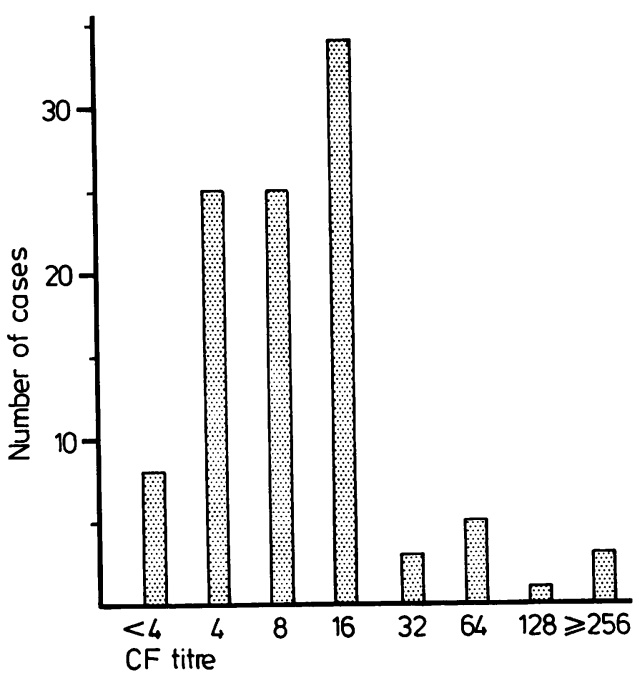

Fig. 3 Distribution of rotavirus complement fixation (NCDV) antibody titres in convalescent sera of 103 children in whom rotavirus antigen was demonstrated in the stools at the acute stage of diarrhoea.

Table 2 Comparison of electron microscopical examination with radioimmunoassay in 125 cases of rotavirus-associated diarrhoea

\begin{tabular}{lll}
\hline & RIA-positive & $\begin{array}{l}\text { RIA-negative } \\
\text { diagnosis by serology }\end{array}$ \\
\hline EM positive & 88 & 0 \\
EM negative & 20 & 17 \\
\hline
\end{tabular}

Table 3 Adenovirus-associated cases of diarrhoea with no evidence of concomitant rotavirus or bacterial pathogen

\begin{tabular}{|c|c|c|c|c|}
\hline \multirow{2}{*}{$\begin{array}{l}\text { Age } \\
\text { (months) }\end{array}$} & \multicolumn{2}{|c|}{ Adenovirus in stools } & \multicolumn{2}{|c|}{ Serology by $C F$} \\
\hline & $E M$ & $R I A$ & Acute & Convalescent \\
\hline 4 & + & + & $<4$ & $<4$ \\
\hline 4 & - & + & 8 & 4 \\
\hline 5 & + & + & $<4$ & $<4$ \\
\hline 5 & + & + & $<4$ & 4 \\
\hline 6 & - & + & $<4$ & 32 \\
\hline 7 & - & + & $<4$ & 8 \\
\hline 7 & + & + & $<4$ & 16 \\
\hline 8 & - & + & $<4$ & 4 \\
\hline 16 & - & + & $<4$ & 16 \\
\hline 16 & + & + & $<4$ & $<4$ \\
\hline 18 & + & + & $<4$ & $<4$ \\
\hline 19 & - & + & $<4$ & 128 \\
\hline 24 & + & + & 8 & 64 \\
\hline 24 & + & + & $<4$ & $<4$ \\
\hline 26 & - & + & 512 & 256 \\
\hline 28 & + & + & 32 & 256 \\
\hline 30 & + & + & $<4$ & $<4$ \\
\hline 35 & + & + & 64 & 64 \\
\hline 51 & - & + & 1024 & 1024 \\
\hline 67 & + & + & $<4$ & 128 \\
\hline
\end{tabular}

and May. Similarly, of the 18 serological diagnoses with negative RIA 10 were made in these months.

The age distribution of the adenovirus-associated cases of diarrhoea was wide (Table 3). Eight patients were infants aged between 4 and 8 months, only four were between 1 and 2 years of age, and eight were older. There was some correlation between the age of the patient and the serological response, as most of those who failed to produce a good CF antibody response by the convalescent stage were young infants.

No adenovirus was detected by RIA in stool specimens at the convalescent stage of 19 patients who had been initially positive. However, adenovirus was detected on two occasions in the convalescent specimens from patients who had been negative for adenovirus at the acute stage of diarrhoea. These 2 children did not have diarrhoea at the time of specimen collection.

Association of viruses and other enteropathogens. Bacterial pathogens were encountered only rarely (Table 4). Enteropathogenic bacteria were found in 29 cases representing $10 \%$ of the total material. In addition $G$. lamblia was demonstrated in 4 cases, but it was not associated with rotavirus or adenovirus infection. Similarly, neither rotavirus nor adenovirus was demonstrated in the 4 children with Salmonella sp. Diarrhoeagenic E. coli (EPEC and ETEC) were isolated both in association with rotavirus and without. Isolations of $C$. jejuni and $Y$. enterocolitica were almost equally divided between viral and apparently non-viral cases of diarrhoea.

Serological evidence (seroconversion or a significant rise in the paired sera studied by CF) of viral 
Table 4 Association of rotavirus and adenovirus with non-viral enteropathogens in 280 cases of diarrhoea in children

\begin{tabular}{|c|c|c|c|c|c|c|c|}
\hline & \multicolumn{3}{|c|}{ Escherichia coli } & \multirow[t]{2}{*}{ Salmonella sp. } & \multirow{2}{*}{$\begin{array}{l}\text { Yersinia } \\
\text { enterocolitica }\end{array}$} & \multirow{2}{*}{$\begin{array}{l}\text { Campylobacter } \\
\text { jejuni }\end{array}$} & \multirow{2}{*}{$\begin{array}{l}\text { Giardia } \\
\text { lamblia }\end{array}$} \\
\hline & $E P E C$ & ETEC & EIEC & & & & \\
\hline $\begin{array}{l}\text { Rotavirus }\left(\mathrm{n}=128^{*}\right) \\
\text { Adenovirus }\left(\mathrm{n}=29^{*}\right) \\
\text { Non-rota, non-adenovirus }(\mathrm{n}=131) \\
\text { Total }\end{array}$ & $\begin{array}{r}4 \\
0 \\
7 \\
11\end{array}$ & $\begin{array}{l}2 \\
0 \\
2 \\
4\end{array}$ & $\begin{array}{l}0 \\
0 \\
1 \\
1\end{array}$ & $\begin{array}{l}0 \\
0 \\
4 \\
4\end{array}$ & $\begin{array}{l}1 \\
0 \\
1 \\
2\end{array}$ & $\begin{array}{l}3 \\
(1) \dagger \\
4 \\
7\end{array}$ & $\begin{array}{l}0 \\
0 \\
4 \\
4\end{array}$ \\
\hline
\end{tabular}

*Includes 8 cases of dual infection with rotavirus and adenovirus. †One case of Campylobacter jejuni isolation was associated with such a dual infection.

Table 5 Serological evidence of associated virus infections in rotavirus diarrhoea and in cases of diarrhoea without demonstrable rotavirus or adenovirus in the stools. Paired sera were collected at the acute stage of the disease and 4 weeks later

\begin{tabular}{|c|c|c|c|c|c|c|c|c|}
\hline & \multirow[t]{2}{*}{ Adenovirus } & \multicolumn{2}{|c|}{ Parainfluenza } & \multirow{2}{*}{$\begin{array}{l}\text { Respiratory } \\
\text { syncytial virus }\end{array}$} & \multirow[t]{2}{*}{ Mycoplasma } & \multirow{2}{*}{$\begin{array}{l}\text { Herpes } \\
\text { simplex }\end{array}$} & \multirow[t]{2}{*}{ Coxsackie B5 } & \multirow{2}{*}{$\begin{array}{l}\text { All } \\
\text { viruses }\end{array}$} \\
\hline & & 2 & 3 & & & & & \\
\hline $\begin{array}{l}\text { Rotavirus }(n=128) \\
\text { Non-rota, non-adenovirus }(n=131) \\
\text { Total }\end{array}$ & $\begin{array}{r}9 \\
9 \\
18\end{array}$ & $\begin{array}{l}2 \\
1 \\
3\end{array}$ & $\begin{array}{l}4 \\
3 \\
7\end{array}$ & $\begin{array}{l}0 \\
1 \\
1\end{array}$ & $\begin{array}{l}\mathbf{0} \\
\mathbf{2} \\
\mathbf{2}\end{array}$ & $\begin{array}{l}0 \\
1 \\
1\end{array}$ & $\begin{array}{l}0 \\
1 \\
1\end{array}$ & $\begin{array}{l}15 \\
18 \\
33\end{array}$ \\
\hline
\end{tabular}

Table 6 Antibiotic treatment before the onset of diarrhoea, and occurrence of respiratory symptoms in relation to viral aetiology of diarrhoea in 259 children

\begin{tabular}{|c|c|c|c|c|c|c|}
\hline \multirow[t]{2}{*}{ Aetiology of diarrhoea } & \multicolumn{2}{|c|}{ Antibiotics } & \multicolumn{2}{|c|}{ Respiratory symptoms } & \multicolumn{2}{|c|}{ Otitis media } \\
\hline & No & $(\%)$ & No & $(\%)$ & No & $(\%)$ \\
\hline $\begin{array}{l}\text { Rotavirus }\left(n=128^{*}\right) \\
\text { Adenovirus }\left(n=29^{*}\right) \\
\text { Non-rota, non-adenovirus }(n=110)\end{array}$ & $\begin{array}{r}17 \\
7 \\
25\end{array}$ & $\begin{array}{l}(13) \\
(24) \\
(23)\end{array}$ & $\begin{array}{r}43 \\
9 \\
28\end{array}$ & $\begin{array}{l}(34) \\
(31) \\
(25)\end{array}$ & $\begin{array}{r}19 \\
9 \\
24\end{array}$ & $\begin{array}{l}(15) \\
(31) \\
(22)\end{array}$ \\
\hline
\end{tabular}

*Includes 8 cases of dual infection of rotavirus and adenovirus.

infection was obtained in 33 cases (Table 5). This figure does not include rotavirus serology or adenovirus serology in cases with demonstrable adenovirus in the stools. As the specimens were collected at 4-weekly intervals it was not possible to ascertain whether the serological diagnoses resulted from a concomitant infection or from a second illness in the meantime. Adenovirus infections occurred most frequently (18 cases); in addition, parainfluenza virus, respiratory syncytial virus, herpes simplex virus, and $M$. pneumoniae were diagnosed. These serological diagnoses of respiratory viruses were evenly distributed between rotavirus-associated and non-rotavirus, non-adenovirus-associated cases of diarrhoea. There was only one case of enterovirus infection demonstrable by a significant rise in coxsackie B5 virus antibodies.

Association of diarrhoea with other clinical conditions. Clinical signs of respiratory tract infection were present at admission or during the duration in hospital in almost one-third of all patients with diarrhoea (Table 6). Otitis media was observed quite often, in about $20 \%$ of the cases. There was no clear difference between the viral and the assumed nonviral cases of diarrhoea in this respect. A small proportion of the respiratory symptoms could be explained by another respiratory virus infection detectable using CF antibody response. There were 5 serological diagnoses among the rotavirus group of diarrhoea with respiratory infection, 1 in the corresponding adenovirus group, and 11 in the nonrotavirus, non-adenovirus group.

Altogether 54 children were receiving or had received antibiotics within 3 days before the onset of diarrhoea. This 'antibiotic-induced' diarrhoea occurred somewhat more often among the nonrotavirus, non-adenovirus-associated cases (23\%) than in the viral diarrhoea group $(13 \%$ for rotavirus, $24 \%$ for adenovirus). Conversely it can also be said that many allegedly antibiotic-induced cases of diarrhoea were in fact associated with, and probably caused by, rotavirus or adenovirus.

\section{Discussion}

Since the discovery of rotavirus there have been several studies on infantile gastroenteritis looking for both viral and bacterial enteropathogens. ${ }^{4-7}$ 10 18-23 It was hoped that this investigation would be a comprehensive study of diarrhoea of children in hospital. We believe that the diagnostic recovery was thorough as we used sensitive methods for rotavirus and adenovirus in the stools, the viral studies were 
complemented by serology of paired sera, and most recognised non-viral enteropathogens were searched for by adequate methods.

Rotavirus diarrhoea appears epidemiologically to form a distinct entity, and this was observed in the present study. Rotavirus was present in $49 \%$ of the cases, which is one of the highest figures to be reported in a 1-year study of children. It is unlikely that many cases were missed as we used both serology and faecal examination by RIA. RIA had previously been found to be more sensitive that EM for the detection of rotavirus in the stools. ${ }^{28}$ There was a very good correlation between RIA for rotavirus in the stools and serology by CF of paired sera, confirming previous observations on the correlation between EM of stools and serology by CF using NCDV as antigen. ${ }^{24}$ Serological studies complemented the examination of stools by RIA or EM and showed additional cases of rotavirus infection. The relatively long period (about 4 weeks) between the acute and convalescent stage specimens apparently allowed these children to develop detectable antibody responses. ${ }^{18}$

The finding of peak incidence of rotavirus diarrhoea between 7 and 12 months of age is in accordance with previous studies. ${ }^{6} 71924$ The epidemic season lasted until June, which is later than in reports from countries with more temperate climates-such as USA. ${ }^{14}$

The replication of rotavirus is probably limited to the small-intestine, ${ }^{2526}$ and there are no reports of rotavirus outside the gastrointestinal tract. ${ }^{8}$ In view of this it is surprising that respiratory symptoms are so often observed in rotavirus diarrhoea, ${ }^{67}$ as was the case in the present series. Lewis et al. ${ }^{7}$ went so far as to call cases of rotavirus diarrhoea 'rotavirus syndrome' if they were preceded by respiratory symptoms. We could not find such a clear association between rotavirus and respiratory infection. Respiratory infection and otitis were indeed common before and during diarrhoea, but they occurred equally often in adenovirus-associated cases and in patients in whom neither rotavirus nor adenovirus was demonstrated. Use of antibiotics before the onset of diarrhoea was more common in patients with no demonstrable virus, but it also occurred not infrequently in rotavirus-associated diarrhoea. All this probably reflects the fact that in winter, and in young infants of less than 2 years, both respiratory infections and diarrhoea, by rotavirus and other causes, occur frequently and the chance of coincidence is great.

In contrast to rotavirus, the adenovirus-associated cases of diarrhoea do not appear as a distinct subgroup in the series. There was a wide distribution of age and only some seasonal clustering, many cases appeared to be associated with a concomitant rotavirus infection, there were cases with adenovirus in the stools but no serological response and, conversely, many cases of serological diagnosis without adenovirus in the stools. Despite all these arguments it appears that some cases of diarrhoea in the present series were likely to have been caused by adenovirus. Therefore, continuous search for adenoviruses seems worthwhile in children with diarrhoea, whenever a suitable test is available. The present RIA method is convenient and sensitive, and the use of this or comparable enzymatic assays should in the future lead to increased knowledge of the role of adenoviruses in diarrhoea.

The association of stool viruses and enteropathogenic bacteria appears a complicated issue. Looking at the present results one might first conclude that there is no apparent division between bacterial and viral cases of diarrhoea, but enteric bacteria are found with or without rotavirus in a random fashion. Rotavirus gastroenteritis may precede infection by enteropathogenic bacteria by favouring their growth. On the other hand this conventional thinking that viral infection leads to bacterial superinfection may not necessarily always be valid. In the present series in at least two instances infection by enteropathogenic bacteria seemed to precede rotavirus infection, and in several other cases rotavirus and bacteria were present simultaneously. Careful longitudinal follow-up studies are needed.

Finally, one should comment on the $92(35 \%)$ cases of diarrhoea with adequate specimens for viral and bacterial studies but with no demonstrable aetiological agent. These probably form a heterogeneous group. Stool viruses other than rotavirus and adenovirus were not fully covered in this study, but they were not encountered by EM in specimens that had been found positive for rotavirus or adenovirus by RIA. Among these unresolved cases there may also be bacterial diarrhoeas which so far are elusive and this group includes 'true' cases of antibioticassociated diarrhoea, whatever the pathogenic mechanism is. Another explanation for the aetiology in some cases may be 'parenteral' diarrhoea associated with other infections-such as otitis media, pneumonia, or urinary tract infection by a hitherto unknown mechanism. ${ }^{27}$

We thank Ms Taimi Tammipuu, Ms Kerttu Kangas, Ms Tuire Laatta, Ms Leena Soini, and Ms Marita Maaronen for technical assistance, and Ms Terttu Rosenholm for secretarial help.

This work was supported by grants from the Academy of Finland, the Medical Research Council, and the Sigrid Jusélius Foundation. 


\section{References}

1 Bishop R F, Davidson G P, Holmes I H, Ruck B J. Virus particles in epithelial cells of duodenal mucosa from children with acute non-bacterial gastroenteritis. Lancet 1973; ii: 1281-3.

2 Flewett T H, Bryden A S, Davies H. Letter; Virus particles in gastroenteritis. Lancet 1973; ii: 1497.

3 Anonymous. Rotavirus gastroenteritis. $\mathrm{Br} \mathrm{Med} \mathrm{J} \mathrm{1977;}$ ii: $784-5$.

4 Walker-Smith J. Rotavirus gastroenteritis. Arch Dis Child 1978; 53: 355-62.

5 Madeley C R, Cosgrove B P, Bell E J, Fallon R J. Stool viruses in babies in Glasgow. I. Hospital admissions with diarrhoea. J Hyg (Camb) 1977; 78: 261-73.

6 Rodriguez W J, Kim H W, Arrobio J O, et al. Clinical features of acute gastroenteritis associated with human reovirus-like agent in infants and young children.J Pediatr 1977; 91 : 188-93.

7 Lewis H M, Parry J V, Davies H A, et al. A year's experience of the rotavirus syndrome and its association with respiratory illness. Arch Dis Child 1979; 54: 339-46.

8 Goldwater P N, Chrystie I L, Banatvala J E. Rotaviruses and the respiratory tract. $\mathrm{Br} \mathrm{Med} J$ 1979; ii: 1551.

9 Retter M, Middleton P J, Tam J S, Petric M. Enteric adenoviruses: detection, replication, and significance. J Clin Microbiol 1979; 10: 574-8.

10 Bryden A S, Davies H A, Hadley R E, Flewett T H, Morrison C A, Oliver P. Rotavirus enteritis in the west Midlands during 1974. Lancet 1975; ii: 241-3.

11 Birch C J, Lewis F A, Kennett M L, Homola M, Pritchard H, Gust I D. A study of the prevalence of rotavirus infection in children with gastroenteritis admitted to an infectious diseases hospital. J Med Virol 1977; 1: 69-77.

12 Gary G W, Jr, Hierholzer J C, Black R E. Characteristics of noncultivable adenoviruses associated with diarrhea in infants: a new subgroup of human adenoviruses. J Clin Microbiol 1979; 10: 96-103.

13 Appleton H, Buckley M, Robertson M H, Thom B T. A search for faecal viruses in new-born and other infants. J Hyg (Camb) 1978; 81 : 279-83.

14 Brandt C D, Kim H W, Yolken R H, et al. Comparative epidemiology of two rotavirus serotypes and other viral agents associated with pediatric gastroenteritis. Am J Epidemiol 1979; 110: 243-54.

15 Sarkkinen H K, Halonen P E, Arstila P P. Comparison of four-layer radioimmunoassay and electron microscopy for detection of human rotavirus. J Med Virol 1979; 4: 255-60.
16 Sarkkinen H K, Meurman O H, Halonen P E. Solid phase radioimmunoassay of IgA, IgG, and IgM antibodies to human rotavirus. $J$ Med Virol 1979; 3 : 281-9.

17 Mäki M, Vesikari T, Grönroos P. Enterotoxigenic and invasive Escherichia coli as causes of childhood diarrhoea in Finland. Acta Paediatr Scand 1980; 69: 219-24.

${ }^{18}$ Kapikian A Z, Kim H W, Wyatt R G, et al. Human reovirus-like agent as the major pathogen associated with winter gastroenteritis in hospitalized infants and young children. N Engl J Med 1976; 294: 965-72.

19 Carr M R, Donald G, McKendrick W, Spyridakis T. The clinical features of infantile gastroenteritis due to rotavirus. Scand J Infect Dis $1976 ; 8$ : 241-3.

20 Gurwith M J, Williams T W. Gastroenteritis in children: a two-year review in Manitoba. I. Etiology. J Infect Dis 1977; 136: 239-47.

21 Echeverria P, Ho M T, Blacklow N R, et al. Relative importance of viruses and bacteria in the etiology of pediatric diarrhea in Taiwan. $J$ Infect Dis 1977; 136: 383-90.

22 Pickering L K, Evans D J, Jr, Munoz O, et al. Prospective study of enteropathogens in children with diarrhea in Houston and Mexico. J Pediatr 1978; 93: 383-8.

${ }^{23}$ Hieber J P, Shelton S, Nelson J D, Leon J, Mohs E. Comparison of human rotavirus disease in tropical and temperate settings. Am J Dis Child 1978; 132: 853-8.

24 Tufveson B, Johnsson T. Occurrence of reo-like viruses in young children with acute gastroenteritis. Diagnoses established by electron microscopy and complement fixation, using the reo-like calf virus as antigen. Acta Pathol Microbiol Scand $[B]$ 1976; 84: 22-8.

25 Theil K W, Bohl E H, Cross R F, Kohler E M, Agnes A G. Pathogenesis of porcine rotaviral infection in experimentally inoculated gnotobiotic pigs. Am J Vet Res 1978; 39: 213-20.

26 Middleton P J. Pathogenesis of rotaviral infection. $\mathrm{J} \mathrm{Am}$ Vet Med Assoc 1978; 173: 544-6.

27 Nelson J D. Diarrhea. In: Vaughan V C, McKay R J, Jr, Behrman R E, eds. Nelson textbook of pediatrics, eleventh edition. Philadelphia: Saunders, 1979: 710-2.

28 Halonen P, Sarkkinen H, Arstila P, Hjertsson E, Torfason E. A four-layer radioimmunoassay for detection of adenovirus in stool. J Clin Microbiol 1980; 11 : 614-7.

Correspondence to Dr Timo Vesikari, Department of Paediatrics, Tampere Central Hospital, 33520 Tampere 52, Finland.

Received 22 January 1980 